\title{
Assessment of Knowledge and Attitude of Medical Practitioners Towards Pediatric Dental Care in Raichur District, Karnataka, India-A Survey
}

\author{
${ }^{1}$ Dhanu G Rao, ${ }^{2}$ Shamama Sheereen, ${ }^{3}$ Raghavendra Havale, ${ }^{4}$ Shrutha S Prakasha, ${ }^{5}$ Manva M Zulfikar
}

\begin{abstract}
Aim: To determine the knowledge and attitude of medical practitioners towards dental care of children in Raichur district.

Materials and methods: The present study is a crosssectional survey conducted among the medical practitioners of Raichur district. The study was conducted on 300 practitioners, randomly selected. The data pertaining to their knowledge and attitude about oral health was gathered using a self-administered questionnaire. Data were analyzed using descriptive studies.
\end{abstract}

Results: Among the study subjects, $32.7 \%$ of the respondents could recognize the precancerous and cancerous lesions in the oral cavity. A total of $65.3 \%$ considered that dental caries is not infectious. About $52.7 \%$ of the physicians thought that scaling causes tooth sensitivity and only $22.7 \%$ knew that tooth brushing should be initiated after the eruption of the first milk tooth.

Conclusion: Medical practitioners had a moderate knowledge and attitude towards pediatric dental care.

Keywords: Attitude, Knowledge, Medical practitioner.

How to cite this article: Rao DG, Sheereen S, Havale R, Prakasha SS, Zulfikar MM. Assessment of Knowledge and Attitude of Medical Practitioners Towards Pediatric Dental Care in Raichur District, Karnataka, India-A Survey. Int J Clin Pediatr Dent, 2018;11(5):375-381.

Source of support: Nil

Conflict of interest: None

\section{INTRODUCTION}

One of the significant challenges posed by the dental fraternity is the maintenance of a population with good oral health. The dental disorder is not just a minor disease of the gums and teeth, but a disease of the body that happens to commence in the oral cavity. ${ }^{1}$ Medical prac-

\footnotetext{
${ }^{1,3}$ Professor, ${ }^{2}$ Postgraduate Student, ${ }^{4}$ Reader, ${ }^{5}$ Senior Lecturer

${ }^{1-4}$ Department of Pedodontics and Preventive Dentistry, AME's Dental College and Hospital, Bengaluru, Karnataka, India

${ }^{5}$ Department of Conservative Dentistry and Endodontics, AME's Dental College and Hospital, Bengaluru, Karnataka, India

Corresponding Author: Shamama Sheereen, Postgraduate Student, Department of Pedodontics and Preventive Dentistry, AME's Dental College and Hospital, Bengaluru, Karnataka, India, Phone: 9743550921, e-mail: shamama228@gmail.com
}

titioners especially the pediatrician and gynecologist are the first to get in touch with the child since birth and has a responsibility to educate the parents. Thus, the physicians are in the supreme position to align parents regarding the prevention of oral diseases and impart knowledge leading to healthy oral environment. ${ }^{2}$ Thereby, it is preferable for the physicians to possess the fundamental dental understanding to unmask signs and symptoms of dental diseases. Very few studies have collected data concerning the dental knowledge of physicians. The present study seeks to assess the knowledge and attitude of medical practitioners towards child dental care.

\section{MATERIALS AND METHODS}

A cross-sectional survey was conducted among the medical practitioners of Raichur district, Karnataka. A simple random sampling was done. Sample size of 300 medical practitioners was decided. Data regarding their knowledge and attitude towards dental health was gathered using a self-administered questionnaire comprising of 25 closeended questions divided into two sections. One section contained the questions to assess the knowledge and the other section for attitude. The investigator approached each practitioner personally and distributed the questionnaire. It was informed that responses would remain anonymous. At the end of the questionnaire queries about their personal details like name, gender, and medical specialty were recorded. The filled questionnaire was immediately collected within 20 minutes and analyzed.

\section{Inclusion Criteria}

The practitioners should have registered in the Karnataka state medical council.

- They should be practicing in Raichur district.

- They should either be pursuing postgraduation or should have completed their postgraduate course.

\section{Scoring Criteria}

The scores were assessed as follows:

- $<50 \%$ : Poor

- 50 to $75 \%$ : Moderate

- >75\%: Good 


\section{Statistical Analyses}

Descriptive statistics such as frequency and percentage was used to present the data. Data analysis was done by using Microsoft Excel.

\section{RESULTS}

Responses of the study subjects on polar questions based on their knowledge and attitude towards pediatric dental care are tabulated in Table 1 . The results showed that $67.3 \%$ of the practitioners knew that pediatric dentistry is a specialty. About $32.7 \%$ of the respondents could recognize the precancerous and cancerous lesions in the oral cavity. Almost half of the practitioners were not aware that dental sealants will prevent caries.

A total of $67.3 \%$ were aware that pregnant women need a dental check-up, $65.3 \%$ considered that dental caries is not infectious and only $16 \%$ knew it is transmissible from mother to child. The graphical representation of the polar question on knowledge is illustrated in Graph 1 and attitude in Graph 2.

Table 1: Polar questions based on knowledge and attitude

\begin{tabular}{lll}
\hline Polar questions based on knowledge & Yes (\%) & No (\%) \\
\hline Is treating deciduous teeth important? & 67.3 & 32.7 \\
Consider oral examination as a part of routine general check up? & 60.7 & 39.3 \\
Aware of the existence of pediatric dentistry & 67.3 & 32.7 \\
as an exclusive specialty? & & \\
Able to recognize the precancerous and & 32.7 & 67.3 \\
cancerous lesions in the oral cavity? & & \\
Relation between long term breastfeeding/ & 61.3 & 38.7 \\
bottle feeding on dentition? & & \\
Familiar with the effect of fluoride on oral health? & 72.7 & 27.3 \\
Oral habits affect the dentition of the child? & 70.7 & 29.3 \\
Aware of fluoride toothpaste in preventing & 76.7 & 23.3 \\
dental caries? & & \\
Aware of fluoride sealants? & 43.3 & 56.7 \\
Relation between oral health and general health & 86.7 & 13.3 \\
Can untreated dental disease lead to systemic complications? & 77.3 & 22.7 \\
Polar questions based on attitude & yes (\%) & no (\%) \\
Pregnant women need dental check up? & 67.3 & 32.7 \\
Educate your patients about importance of oral health? & 72.7 & 27.3 \\
Is dental caries an infectious disease? & 34.7 & 65.3 \\
Is dental caries transferred from mother to child? & 16.0 & 84.0 \\
Interested to receive oral health care training? & 84.0 & 16.0 \\
Is dental wing necessary in rural areas? & 90.0 & 10.0 \\
\hline
\end{tabular}

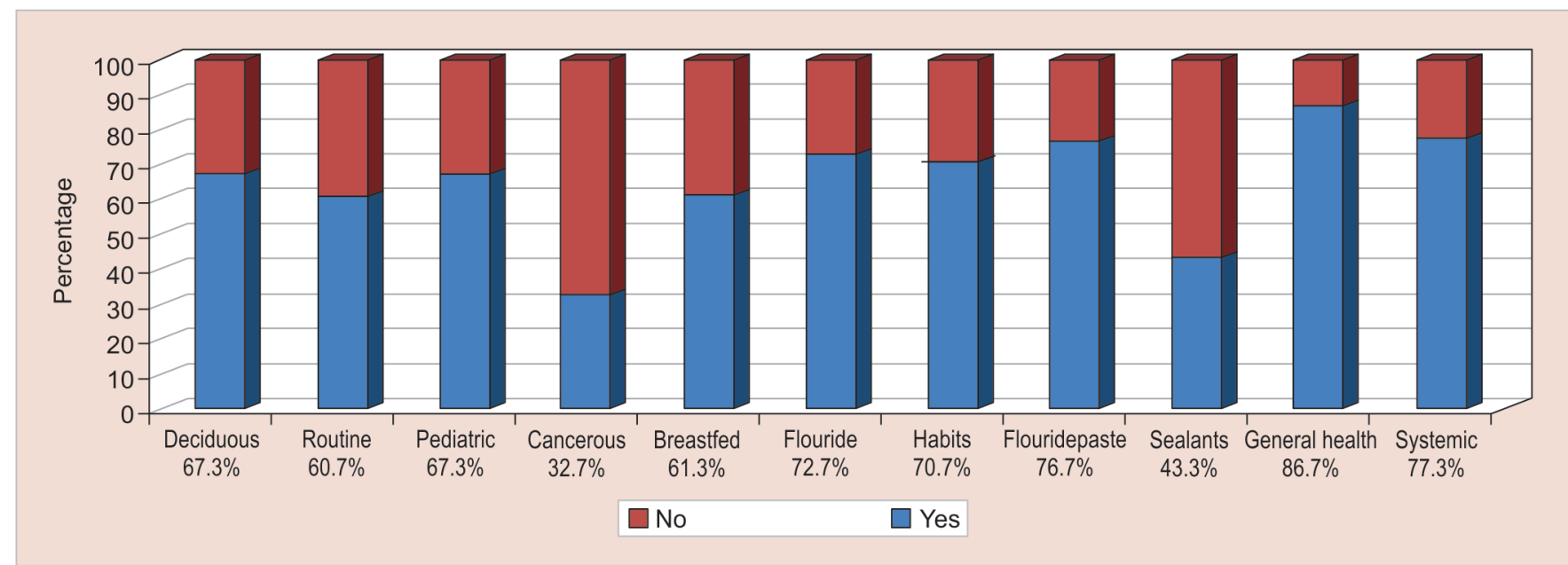

Graph 1: Response of study subjects on polar questions based on dental knowledge 


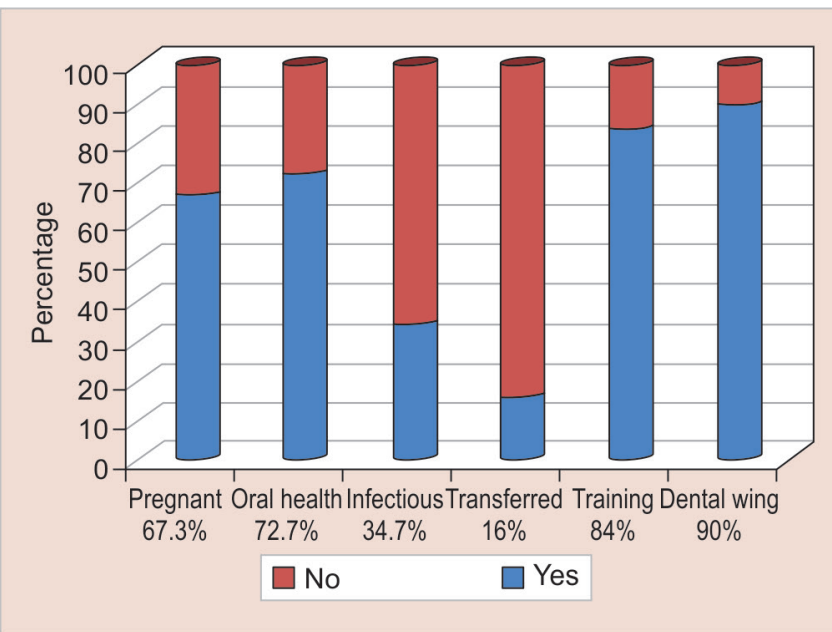

Graph 2: Response of study subjects on polar questions based on dental attitude
Table 2 displays the response on multiple choice questions (MCQs). The results indicate that about $52.7 \%$ of physicians thought that scaling causes tooth sensitivity. Only $22.7 \%$ of respondents knew that tooth brushing should be initiated after the eruption of the first milk tooth and $28.75 \%$ answered that frequency of dental visits is once in 6 months. Graphs 3 and 4 summarize the response of the MCQs on knowledge and attitude respectively.

The results of the study revealed that the knowledge and attitude of medical practitioners towards pediatric dental health was moderate.

\section{DISCUSSION}

Medical practitioners are considered the primary bond between dentists and children. Dental diseases can be

Table 2: Multiple choice questions based on knowledge and attitude

\begin{tabular}{|c|c|}
\hline \multicolumn{2}{|l|}{ MCQs based on knowledge } \\
\hline Common causes of dental problems? & Percentage \\
\hline Poor oral hygiene & 33.3 \\
\hline Eating excess sweet & 2.0 \\
\hline Hereditary & 1.3 \\
\hline All the above & 63.3 \\
\hline Common cause of pain in the oro facial region? & Percentage \\
\hline Decayed tooth & 30.7 \\
\hline Gum problems & 7.3 \\
\hline Referred pain from other parts of the body & 2.0 \\
\hline All the above & 60.0 \\
\hline Adverse effect of scaling on teeth? & Percentage \\
\hline Tooth sensitivity & 52.7 \\
\hline Thinning of teeth & 20.7 \\
\hline Increase in mobility & 2.0 \\
\hline No effect & 24.7 \\
\hline In your clinic if you come across a child with dental problems, whom would you refer the child to? & Percentage \\
\hline General dentist & 30.0 \\
\hline Pedodontist & 52.0 \\
\hline No referral & 18.0 \\
\hline \multicolumn{2}{|l|}{ MCQs based on attitude } \\
\hline First dental visit for a child? & Percentage \\
\hline When the baby is 6 months & 25.3 \\
\hline When the baby is one year & 15.3 \\
\hline After eruption of a few milk teeth & 39.3 \\
\hline Dental caries present & 20.0 \\
\hline What do you do if a patient with dental abscess reports to your clinic? & Percentage \\
\hline Refer the patient to dentist & 69.3 \\
\hline Only prescribe medications & 22.7 \\
\hline Ignore & 8.0 \\
\hline Commencement of tooth brushing? & Percentage \\
\hline After the eruption of first milk tooth & 22.7 \\
\hline After eruption of a few milk teeth & 50.0 \\
\hline After eruption of all milk teeth & 15.3 \\
\hline Only after eruption of permanent teeth & 12.0 \\
\hline Frequency of dental visits? & Percentage \\
\hline Once in 6 months & 28.7 \\
\hline Once in a year & 50.0 \\
\hline Only if in pain & 5.3 \\
\hline When dental caries is noticed & 16.0 \\
\hline
\end{tabular}



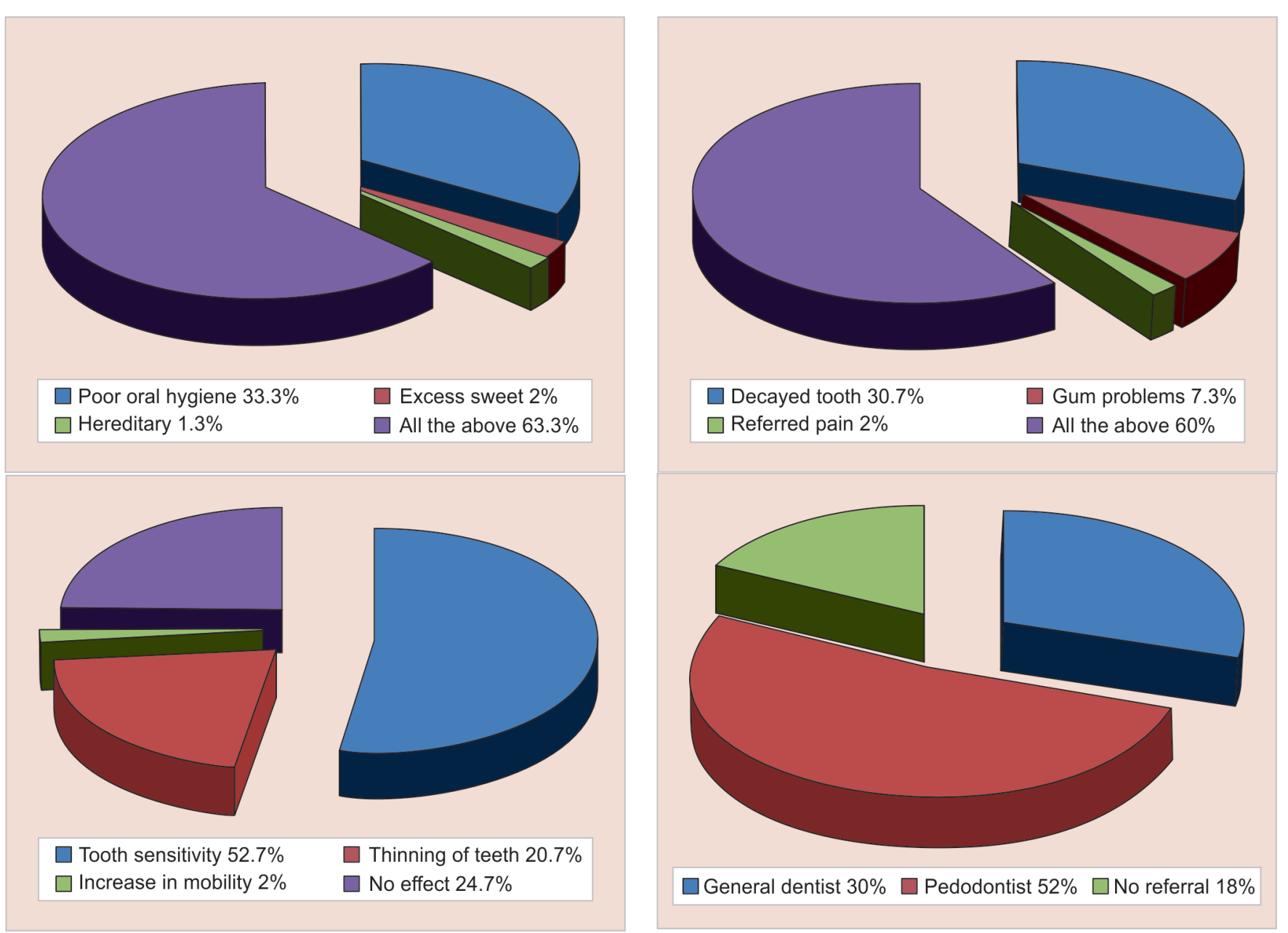

Graph 3: Response of study subjects on MCQs based on dental knowledge

treated at early stages if the physicians examine the oral cavity regularly. This study emphasizes the crucial role that the physicians can play to enhance oral public health.

In the present study with regards to dental knowledge, $67.3 \%$ of medical practitioners knew the importance of treating deciduous teeth and $60.7 \%$ of the respondents examined oral cavity routinely. However, Al-Hussyeen et al. reported that almost half of pediatricians did not routinely include dentition in their examinations. $^{3}$

Only $32.7 \%$ of the doctors were able to recognize the precancerous and cancerous lesions in the oral cavity which is in correlation with the study conducted by Umesh et al. ${ }^{4}$ Participants stated that lack of knowledge regarding early signs and symptoms was a major hindrance to the diagnosis of oral pre-cancer and early cancer. ${ }^{5}$

Among the surveyed doctors $61.3 \%$ were familiar with the harmful effects of long-term breastfeeding/ bottle feeding. Appropriate breastfeeding is considered the best feeding method for infants. But, certain feeding habits like nocturnal breastfeeding, at will-breast feeding, and weaning delayed beyond the age of 2 years could all harm the dentition. ${ }^{6-8}$ Sabbagh et al. found the majority of pediatricians $(81.3 \%)$ were familiar with the harmful effects of night breastfeeding. ${ }^{6}$ In a previous study by Murthy et al. more than $50 \%$ of doctors felt that only bottle fed children get ECC. But there is evidence to show that infants who sleep with the mother and nurse throughout the night are prone to increased caries risk. ${ }^{9-11}$

With regards to fluoride, $72.7 \%$ of the practitioners were aware of the effect of fluoride on oral health, awareness of fluoride toothpaste existed among $76.7 \%$ of the respondents, and the knowledge of fluoride sealants was prevalent amongst nearly half of the participants (43.3\%). As investigated by Poornima et al. the pediatricians' knowledge of caries prevention and potentials of fissure sealants were found to be limited, considering that $64 \%$ of pediatricians did not even know what fissure sealants were. ${ }^{2}$ Similar results were also reported by previous studies. $3,12,13$

Oral habits include digit sucking, pacifier sucking, lip sucking and biting, nail-biting, bruxism, self-injurious habits, mouth breathing, and tongue thrust. Among the respondents, $70.7 \%$ were aware that oral habits affect the dentition of the child. The physicians can provide the parents with information regarding the consequences of a habit. 

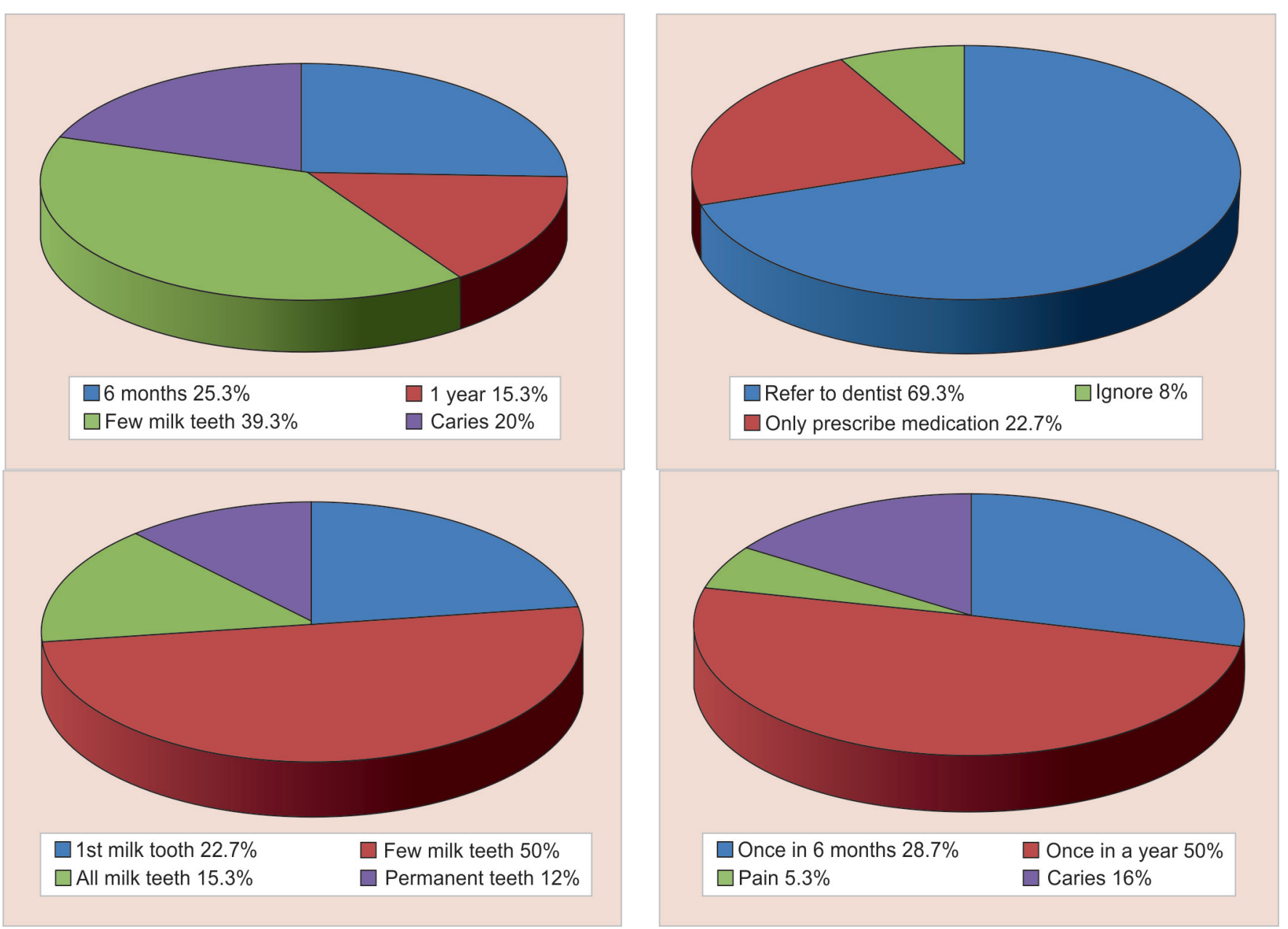

Graph 4: Response of study subjects on MCQs based on dental attitude

Among the investigating population, $86.7 \%$ were well acquainted of the relation between oral and general health, while the knowledge was slightly higher among the doctors in a study conducted by Ashok et al. ${ }^{1}$ The harmful role of gum/periodontal disease in many serious and life-threatening diseases is evident from recent studies. For example, periodontal disease is associated with coronary heart disease; diabetes; low pre-term birth weights; respiratory disease; improper digestion; osteoporosis; stress the immune system; lower resistance to infections; and minimizes life expectancy. ${ }^{14-18}$ In the present study, most of them $(77.3 \%)$ have rightly answered that untreated dental disease can lead to systemic complications.

Pregnancy is an essential phase in a woman's life, and good oral health is essential for the mother and the baby as well. Although prenatal education is considered the key to dental care of the infant, proper instructions regarding oral health are not delivered to the pregnant women. ${ }^{19}$ Among the study subjects, $67.3 \%$ suggested the need for a dental checkup in pregnant women whereas Srinidhi et al. published a study in which a majority $(91 \%)$ of the practitioners were aware of its significance. ${ }^{20}$
The present study showed that more than half $(72.7 \%)$ of the doctors alert their patients about the importance of oral health. Among the participants, $65.3 \%$ were unaware that dental caries is a disease which is infectious. Only $16 \%$ of them knew that cavity-causing bacteria could be transmitted from the mother to children, which is also cited in the pediatric literature. ${ }^{21}$ S. mutans can be transmitted by Vertical transmission (from mother to child) and/or horizontal transmission (between members of a group e.g. family members or students in a classroom). Poor maternal oral hygiene, dietary habits, child-rearing habits, sharing food and utensils, breastfeeding and sleeping beside the mother, were all significantly associated with colonization of S. mutans. The major source from which infants acquire $S$. mutans is their mothers. ${ }^{22-25}$

Since majority were not trained with respect to oral health aspects, $84 \%$ of the respondents showed their interest to receive oral health care training and $90 \%$ recommended for a dental wing in primary health centers.

When questioned about the common causes of dental problems, $33.3 \%$ of the doctors thought it could be because of poor oral hygiene, $2 \%$ because of excess sweet and $1.3 \%$ said heredity, while $63.3 \%$ believed that dental problems are multifactorial. 
On investigation about the common cause of pain in the orofacial region, $30.7 \%$ said decayed tooth could be the etiology, $7.3 \%$ opted for gum problems, and $2 \%$ of the practitioner's reflection was on referred pain from other parts of the body while $60 \%$ answered for all of the above factors.

When asked to reflect their views on scaling, only $24.7 \%$ have answered the correct option that scaling does not have any adverse effect on teeth. While $52.7 \%$ said scaling results in tooth sensitivity, $20.7 \%$ responded thinning of teeth, $2.0 \%$ said the increase in mobility.

Among the participants, $67.3 \%$ of the doctors were aware of the existence of pediatric dentistry as an exclusive specialty. Only $52 \%$ of practitioners referred children to a pedodontist while 30\% refer to a general dentist. In a study conducted by Poornima et al. ${ }^{2}$ around $86 \%$ of pediatricians referred children with oral disease/dental caries to pedodontist.

When investigated about the first dental visit, $25.3 \%$ of the practitioners suggested the parents for the first dental visit of the child at 6 months of age, 15.3\% when the baby is one year and $39.3 \%$ after the eruption of a few milk teeth. Early visits to the dentist are recommended since it facilitates preventive measures, early diagnosis, alignment regarding proper diet and nutrition, oral hygiene instructions and prevention of non-nutritive sucking habit. ${ }^{26-28}$

According to the American Academy of Pediatric Dentistry (AAPD) guidelines, tooth brushing should be initiated after the eruption of first milk tooth and the AAPD recommends for a biannual dental visit. ${ }^{29}$ In the present study, half of the doctors thought tooth brushing should be initiated after the eruption of a few milk teeth and only $22.7 \%$ of them rightly counseled the parents for brushing after the eruption of first milk tooth. Murthy and Mohandas reported $33.3 \%$ of physicians recommended commencement of tooth brushing after the eruption of first milk tooth. ${ }^{9}$

Regarding the frequency of dental visits, only $28.7 \%$ of the respondents suggested their patients visit the dentist once in six months while $50 \%$ thought once in a year. Chandra et al. ${ }^{30}$ revealed that regular visit of once in six months was suggested by $86.3 \%$ of practitioners which is high when compared with the present study.

In Raichur, people lack awareness pertaining to the oral health. One of the reasons may be that Raichur district comes under Hyderabad Karnataka region which is considered as the underdeveloped region with low socioeconomic status and poor education. This makes the physician's role critical. Medical practitioners are considered as social health reformers in delivering knowledge to the common masses.

\section{LIMITATION}

The limitation of the survey was the inability to use openended questions to probe the participant's responses to a greater extent.

\section{CONCLUSION}

The study indicates that the practitioners had moderate knowledge and attitude towards pediatric dental health. They feel they have a crucial role to be played in the promotion of oral health, but since they are not well acquainted with oral health issues and have not received much dental health education, it makes it difficult for them to promote prevention of dental diseases. Thereby appropriate steps have to be taken for a better understanding of the dental related issues.

\section{RECOMMENDATIONS}

- Collaboration between dentists and medical practitioners for implementation of oral health programs and seminars.

- To inspire the establishment of associate clinics which includes providing medical and dental services under one roof.

- Publish the preventive dentistry articles in medical journals.

- Imparting oral health education in the form of brochures, posters, etc.

- Establish a dental home along with the medical home. These measures help in establishing a good rapport between the dentist and medical practitioners and helps to impart oral health knowledge to the medical doctors.

\section{REFERENCES}

1. Patil A, Chavan S, Baghele ON. Awareness of Oral Health among medical practitioners in Sangamner city- A cross sectional Survey. JIDA 2010;4(12):534-536.

2. Poornima P, Bajaj M, Nagaveni NB, Roopa KB, Neena IE, Bharath KP. Evaluation of the knowledge, attitude and awareness in prevention of dental caries amongst pediatricians. International Journal of Community Medicine and Public Health 2015;2(1):64-70.

3. Al-Hussyeen A, Al-Sadhan S, Al-Dhalaan R, AlGhanim B. Pediatricians knowledge and practices towards children's preventive oral health care in Saudi Arabia. Egypt Dent J. 2003;49:827-834.

4. Umesh, Nagesh L, Sangeeta C. Assessment of knowledge, attitude and practices of medical practitioners towards dental care in rural areas of Davangere taluk. International Journal of Current Research 2014;6(10):9275-9278.

5. Carter LM, Ogden GR. Oral cancer awareness of general medical and general dental practitioners. Br. Dent. J. 2007; 203(5):E10. 
6. Sabbagh HJ, El-Kateb M Al Nowaiser A, Hanno AG, Alamoudi $\mathrm{NH}$. Assessment of pediatricians dental knowledge, attitude and behavior in Jeddah, Saudi Arabia. J Clin Pediatr Dent. 2011;35(4):371-376.

7. American Academy of Pediatric Dentistry. Guidelines on periodicity of examination, preventive dental services, anticipatory guidance and oral treatment for children. Reference manual. Pediatr Dent 2008-2009;30(7):112-118.

8. Dini EL, Holt RD, Bedi R. Caries and its association with infant feeding and oral health related behaviours in 3-4 year old Brazilian children. Community Dent Oral Epidemiol 2000;28(4):2418.

9. Murthy GA, Mohandas U. The knowledge, attitude and practice in prevention of dental caries amongst pediatricians in Bangalore: A cross-sectional study. J Indian soc pedod prevent dent 2010;2(28):100-103.

10. Brice DM, Blum JR, Steinberg BJ. The etiology, treatment, and prevention of nursing caries. Compend Contin Educ Dent. 1996;17(1):92-94.

11. Wyne AH, Adenubi JO, Shalan T, Khan N. Feeding and socioeconomic characteristics of nursing caries children in a Saudi population. Pediatr Dent. 1995;17(7):451-454

12. Sanchez OM, Childres NK, Fox L, Bradley E. Physicians views on pediatric preventive dental care. Pediatr Dent 1997;19(6):377-383.

13. Tsamtsouris A, Gavris V. Survey of paediatricians attitude towards pediatric dental health. J Pedo 1990;14(3):152-157.

14. Syrjanen J, Peltola J, Valtonen V, Iivanainen M. Dental infections in association with cerebral infarction in young and middleaged men. Journal of Internal Medicine 1989;225(3):179-184.

15. Umino M, Nagao M. Systemic diseases in elderly dental patients. International Dental Journal 1993;43(3):213-218.

16. Madianos PN, Bobetsis GA, Kinane DF. Is periodontitis associated with an increased risk factor of coronary heart disease and preterm and/or low birth weight births. Journal of Clinical Periodontology 2002;29:22-36.

17. Moreu G, T Ellez L, Gonza'lez-Jaranay M. Relationship between maternal periodontal disease and low-birth-weight pre-term infants. J Clin Periodontol 2005;32(6):622-627.
18. Hämäläinen $\mathrm{P}$, Meurman $\mathrm{JH}$, Kauppinen $\mathrm{M}$, Keskinen $\mathrm{M}$. Oral infections as predictors of mortality: Gerodontology 2005;22(3):151-157.

19. kumari NR, Sheela S, Sarada PN. Knowledge and attitude on infant oral health among graduating medical students in Kerala. J Indian Soc Pedod Prev Dent 2006;24(4):173-176.

20. Srinidhi S, Ingle NA, Chaly PE, Reddy C. Dental Awareness and Attitudes among Medical Practitioners in Chennai. J Oral Health Comm Dent 2011;5(2):73-78.

21. Hale KJ. American academy of Paediatrics policy statement. Oral health risk assessment timing and the establishment of the dental home. Pediatrics. 2003;111(5 Pt 1):1113-1116.

22. Masuda N, Tsutsumi N, Sobue S, Hamada S. Longitudinal survey of the distribution of various serotypes of Streptococcus mutans in infants. J Clin Microbiol 1979;10(4):497-502.

23. Caufield PW, Cutter GR, Dasanayake AP. Initial acquisition of mutans streptococci by infants: Evidence for a discrete window of infectivity. J Dent Res 1993;72(1):37-45.

24. Karn TA, O'Sullivan DM, Tinanoff N. Colonization of mutans streptococci in 8- to 15-month-old children. J Public Health Dent 1998;58(3)248-249.

25. Wan AK, Seow WK, Purdie DM, Bird PS, Walsh LJ, Tudehope DI. A longitudinal study of Streptococcus mutans colonization in infants after tooth eruption. J Dent Res 2003;82(7):504-508.

26. Brickhouse TH, Unkel JH, Kancitis I, Best AM, Davis RD. Infant oral health care: a survey of general dentists, pediatric dentists, and paediatricians in Virginia. Pediatr Dent. 2008;30(2):147-153.

27. Nowak AJ, Casamassimo PS. The dental home: a primary care, oral health concept. J Am Dent Assoc. 2002;133(1):93-98.

28. American Academy of Pediatric Dentistry. Policy on the dental home. Ref Manual. 2010;32:25-26.

29. American Academy of Pediatric Dentistry policy statement. Pediatr Dent 2009;31(1):302.

30. Chandra J, Chandu GN, Prashant GM, Nagendra J, Shafiulla M, Reddy VS. Dental awareness and attitudes of medical practitioners of Davangere city. Journal of Indian Association of Public Health Dentistry 2006;4(8)38-43. 